\section{On to the second generation}

\section{Robin J. Leatherbarrow}

IT is only four years since catalytic antibodies were first produced ${ }^{1.2}$, yet at a recent meeting* the talk was of the latest second-generation molecules that promise increased efficiency, greater applicability and increased ease of generation. Although designer catalysts cannot yet be produced on demand, the principles are now better understood and it will surely not be too long before tailored syntheses that require stereochemical control can be attempted ${ }^{3}$.

Current ideas on enzyme catalysis stem from Linus Pauling (reviewed in ref. 4). Enzymes catalyse reactions by binding, and hence stabilizing, the transition state of the reaction in preference to the ground state. Antibodies are extremely efficient at binding, but do so to the ground state. Construction of antibody catalysts rests on the assumption that the difference between antibodies and enzymes is not fundamental, but merely one of specificity - over 20 years ago Jencks suggested that if antibodies could be persuaded to bind to transition states, then they should, in theory, acquire catalytic properties 5 . For the first generation of catalytic antibodies, transition-state analogues have been used for immunization in an attempt to fool the immune system into producing antibodies that possess transition-state specificity. This is followed by screening for antibodies that are catalytically active, but the process is inefficient and time consuming. One of the principal aims of current research is to reduce the amount of screening, or eliminate it completely.

Since its inception, the field has been a melting pot for exponents of immunology, chemistry and genetics - all of these techniques are being used in the drive for increased efficacy. Physical organic chemistry has so far been at the heart of things, and the synthesis of transition-state analogues remains a primary requirement. But when looking at how enzymes achieve catalysis, it is clear that transition-state stabilization alone is not sufficient, and S. J. Benkovic (Pennsylvania State University), K. Janda and R. A. Lerner (Scripps Clinic, La Jolla) presented work showing that a catalytic antibody which promotes anilide and ester hydrolysis does so by way of a putative substrate-antibody intermediate. Enzymes usually contain specific functional groups that take part in the reaction, for example carboxylate groups that act as general-base catalysts, or nonprotein cofactors. Clever synthesis can select for catalytic groups in the binding

*Ciba Foundation Symposium 159 on Catalytic Antibodies, London, 1-3 October 1990. The proceedings will be published by Wiley in June 1991. site, using antigens capable of making complementary electrostatic interactions. For instance, a positive charge introduced into the antigen will tend to be bound by antibodies that have a complementary carboxylate in their active site $(\mathrm{K}$. Shokat and P. G. Schultz, University of California, Berkeley), and antibodies that catalyse $\beta$-elimination reactions have

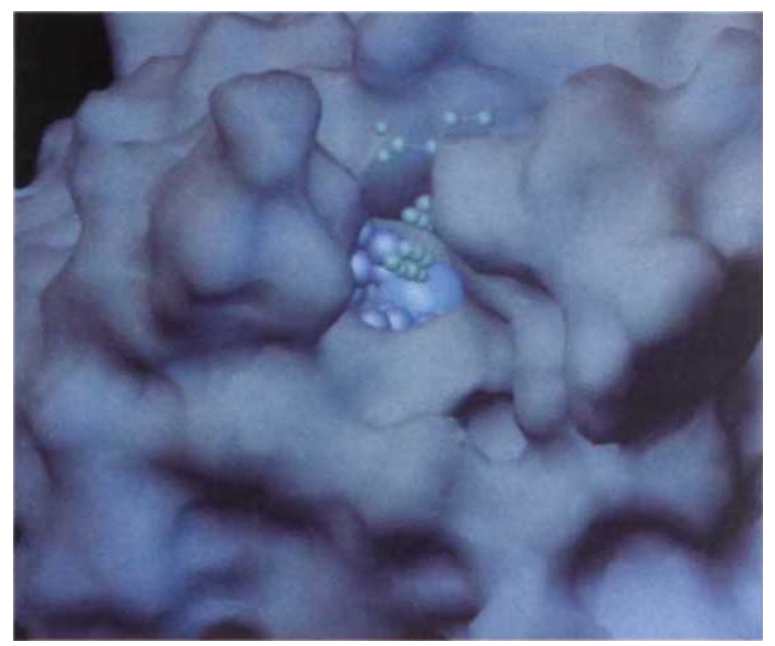

Design of a cofactor-binding site in antibodies ${ }^{7.8}$. The zincligating histidine residues (silver spheres) of carbonic anhydrase were incorporated into the light chain of an antifluorescein antibody (grey solvent-accessible surface). The genetically remodelled antibody binds metal and antigen simultaneously, with the zinc atom (blue) positioned to interact with the fluorescein antigen (green spheres and bonds). (Computer graphics by Michael Pique, Victoria Roberts and John Tainer, Scripps Clinic.) been generated by this process ${ }^{6}$

More direct ways of introducing catalytic groups are also being tried. The most common cofactor in enzyme-catalysed reactions is a metal ion, and in recent experiments $^{7.8}$ a metal coordination site has been introduced into the light chain of an antibody, next to the antigen-binding site (Lerner and Benkovic: see figure). The metal coordination site is based on the $\mathrm{Zn}^{2+}$ site of the enzyme carbonic anhydrase, and comprises three histidinc side chains which are incorporated into the antibody by site-directed mutagenesis. The vacant fourth coordination site will, it is hoped, be in a suitable position to interact with a bound antigen. The engineered antibody specifically binds zinc or copper ions, with an affinity constant of $10^{6} \mathrm{M}^{-1}$, and this may well be a basis for generating catalytic antibodies by combining the engineered light chain with a heavy chain that confers specificity for a given substrate. Metal cofactors have also been tried in conjunction with substrates", but building them into the antibody should be of more general application. Protein engineering is also being used to improve existing catalytic antibodies (A. Plück- thun, Max-Planck-Institute, University of Munich; P.G. Schultz).

In vivo, enzymes acquire their efficiency as a result of evolutionary processes. D. Hilvert (Scripps Clinic) has introduced the gene for a catalytic antibody that has getivity into a strain of yeast that has a defective chorismate mutase enzyme. The original antibody is a relatively poor catalyst, but by applying selection based on genctic complementation it may be possible to 'evolve' the antibody. This will provide valuable information on the evolutionary process itself, and should be a way of making sluggish antibodies more efficient.

Molecular genetics can also offer more efficient screening for catalytic activity ${ }^{11.12}$ (W. Huse, Ixsys Inc., San Diego; Lerner and Benkovic). Current techniques are laborious and probably sample only a small portion of the immunological repertoire, so attempts are being made to express the whole antibody repertoire in Escherischia coli. It should then be possible to screen thousands of antibodyproducing clones with corresponding greater chances of success. Such methods hold great promise, not only for generating catalysts but for producing antibodies in general. However, they may displace the requirement for synthetic chemistry, as screening does not require a transition-state analogue. The coming few years will show whether it proves more effective to produce antibody catalysts from naive immunological repertoires, or to obtain them using mechanism-based antigens. But in either case it is likely that further chemical or genetic modifications will be used to optimize the catalytic activity.

Robin J. Leatherbarrow is in the Department of Chemistry, Imperial College of Science, Technology and Medicine, London SW7 2AY, UK.

\footnotetext{
1. Tramantano, A., Janda, K. \& Lerner, R.A. Science $\mathbf{2 3 4}$ $1566-1570$ (1986)

2. Pollack, S., Jacobs, J. \& Schultz, P.G. Science 234 $1570-1573(1986)$

3. Napper, A.D. Benkovic, S.J., Tramontano, A. \& Lerner, R.A. Science 237, 1041-1043 (1987)

4. Blackburn, M., Kang. A.S., Kingsbury, G.A.\& Burton, D.R. Biochem. J. 262, 381-390 (1989)

5. Jencks, W.P. Catalysis in Chemistry and Enzymology (McGraw-Hill, New York, 1969)

6. Shokat, K.M., Leumann, C.J., Sugasawara, R. \& Schultz, P.G. Nature 338, 269-271 (1989)

Roberts, V.A. et al. Proc. natn. Acad. Sci. U.S.A. 87 6654-6658 (1990)

8. Iverson, B.L. et al. Science 249, 659-662 (1990).

9. Iverson, B.L. \& Lerner. R.A. Science 243, 1104 (1989)

10. Hilvert, D. et al. Proc. natn. Acad. Sci. U.S.A. 85 4953-4955 (1988)

11. Ward, E.S., Güssow, D., Griffiths, A.D., Jones, P.T. \& Winter. G. Nature 341, 544-546 (1989)
}

12. Huse, W.D. et al. Science 246, 1275-1281 (1989) 